\title{
Dimensionless Analysis of Fluid-to-Particle Heat Transfer Coefficients
}

\author{
Paulo N. Baptista, ${ }^{a}$ Fernanda A. R. Oliveira, ${ }^{a *}$ Jorge C. Oliveira ${ }^{a} \&$ \\ Sudhir K. Sastry ${ }^{b}$
}

"Escola Superior de Biotecnologia, Universidade Católica Portuguesa, Rua Dr. António Bernardino de Almeida, 4200 Porto, Portugal

${ }^{h}$ Ohio State University, Agricultural Engineering Department, 590 Woody Hayes Drive, Columbus, OH 43210, USA

\begin{abstract}
Average fluid-to-particle heat transfer coefficients were experimentally determined for spherical aluminium particles heated in carboxymethylcellulose solutions. Two situations were considered: a still particle immersed in a moving fluid, and a particle rotating in an otherwise stagnant fluid. Fluid flow rate, rotating particle velocity, particle diameter and fluid rheological properties were varied, covering a large range of the generalized Reynolds (0 to 801) and Prandtl (69 to 5358) numbers. Average heat transfer coefficients ranged between 56 and $2612 \mathrm{~W} / \mathrm{m}^{2} \mathrm{~K}$. The results were compared with values predicted by published dimensionless correlations, showing that correlations based on a Fröszling-type equation were more adequate. It was found that the contribution due to natural convection should be considered for proper correlation of the results at low Reynolds numbers. The results also show the importance of the fluid velocity profile. (C) 1997 Elsevier Science Limited. All rights reserved
\end{abstract}

\section{NOMENCLATURE}

$a, b, c \quad$ Constants in eqns (1), (12) and (17)

$A_{\mathrm{p}} \quad$ Surface area of the particle $\left(\mathrm{m}^{2}\right)$

$C_{p \mathrm{f}} \quad$ Specific heat capacity of the fluid $(\mathrm{J} / \mathrm{kg} \mathrm{K})$

$C_{p \mathrm{p}} \quad$ Specific heat capacity of the particle $(\mathrm{J} / \mathrm{kg} \mathrm{K})$

$d \quad$ Constant in eqn (17)

*To whom correspondence should be addressed (Fax: 351-2-590351). 


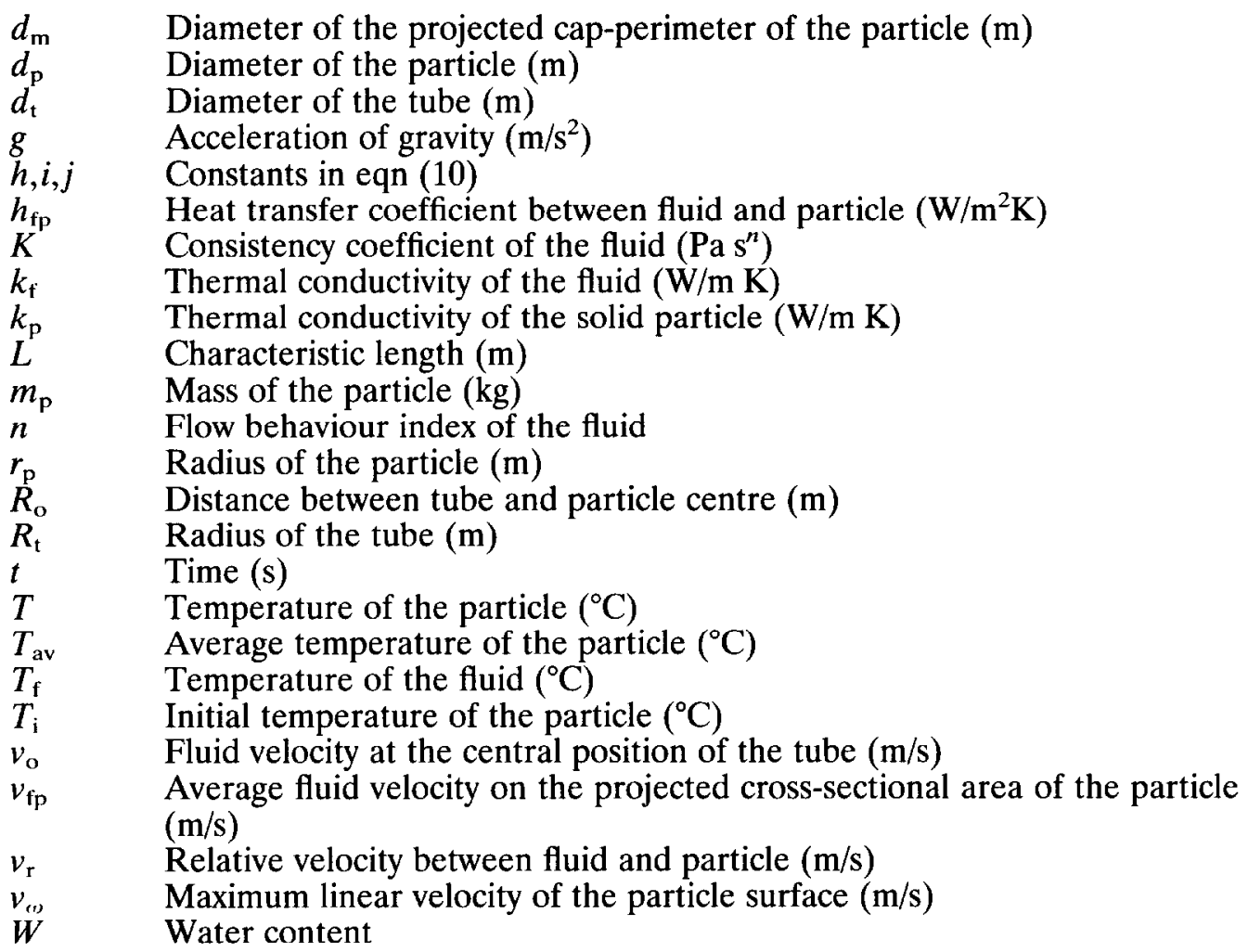

Greek symbols

$\beta \quad$ Volumetric thermal expansion coefficient of the fluid $\left(\mathrm{K}^{-1}\right)$

$\gamma \quad$ Shear rate $\left(\mathrm{s}^{-1}\right)$

$\mu_{\mathrm{b}} \quad$ Newtonian viscosity at the bulk temperature (Pa s)

$\mu_{\mathrm{o}} \quad$ Newtonian viscosity at the wall temperature (Pa s)

$\mu_{\mathrm{s}} \quad$ Intrinsic viscosity (Pa s)

$\rho_{\mathrm{f}} \quad$ Fluid density $\left(\mathrm{kg} / \mathrm{m}^{3}\right)$

$\rho_{\mathrm{p}} \quad$ Particle density $\left(\mathrm{kg} / \mathrm{m}^{3}\right)$

$\tau \quad$ Shear stress $(\mathrm{Pa})$

$\omega \quad$ Rotational velocity of the particle (rev/s)

Dimensionless numbers

$\mathrm{Bi} \quad$ Biot number

$\mathrm{Gr} \quad$ Generalized Grashof number for zero fluid velocity

$\mathrm{Nu} \quad$ Nusselt number

$N u_{0} \quad$ Nusselt number for natural convection

$N u_{\mathrm{s}} \quad$ Nusselt number for natural convection and non-Newtonian fluids

$\mathrm{Pr} \quad$ Prandtl number

$\operatorname{Pr}_{\mathrm{s}} \quad$ Gencralized Prandtl number for zero fluid velocity

$\operatorname{Pr}_{\mathrm{g}} \quad$ Generalized Prandtl number

$\operatorname{Re} \quad$ Reynolds number 
$R e_{\mathrm{g}} \quad$ Generalized Reynolds number

$R e_{\mathrm{w}} \quad$ Reynolds number for rotational velocity

\section{INTRODUCTION}

Knowledge of fluid-to-particle heat transfer coefficients is one of the major problems in the establishment of criteria to process particulate fluid foods aseptically, ensuring adequate lethality and minimizing the loss of nutrients and overall quality. Thermal processing theory has well-established procedures, once the processing time and the heating rate are known. In aseptic processing of particulate foods, both the rcsidence time and the heating rate of the particles are subjects open to discussion. There is insufficient evidence regarding the boundary layer conditions between fluid and particle, and the quantification of convection heat transfer in this complex situation is still at an early stage.

The experimental determination of fluid-to-particle heat transfer coefficients $\left(h_{\mathrm{fp}}\right)$ in continuous flow is a very difficult task and a conservative approach based on a non-flow or stationary condition has been suggested (Dignan et al., 1989). However, several authors reported measured fluid-to-particle heat transfer coefficients in flow conditions that clearly show that this approach is too conservative (Zuritz et al., 1990; Balasubramaniam, 1993; Mwangi et al., 1993; Zitoun \& Sastry, 1994a, 1994b). In fact, particle and fluid often move at different velocities (Palmieri et al., 1992; Dutta 1990a \& Sastry, 1990b), thus inducing forced convection. In addition, the particle may show a rotational movement (Sastry \& Zuritz, 1987), affecting the boundary layer and probably increasing the heat transfer coefficients. The analysis of the heat transfer process between fluid and particles is therefore important for situations where a relative linear velocity or a rotational velocity exists.

Several authors have simulated flow conditions pertaining to the existence of relative linear velocities by maintaining a particle fixed and immersed in a moving fluid inside a cylindrical tube. In this case, the particle does not rotate and there will be a turbulence induced by the impact of the fluid on the particle and consequent streamlines. The experimental data were correlated by dimensionless analysis, which is a type of approach commonly used to characterize the dependence between heat transfer, thermophysical properties of particle and fluid and flow conditions. Maesmans et al. (1992) reviewed published fluid-to-particle heat transfer coefficients in heterogeneous foods. Table 1 summarizes published dimensionless correlations for estimating the Nusselt number. Forced convection was considered dominant, with the exception of the work of Awuah et al. (1993), where natural convection was considered to prevail. Most equations in Table 1 are of the Fröszling type, having the general form:

$$
N u=N u_{\mathrm{o}}+a \operatorname{Re}^{b} \operatorname{Pr}^{c}
$$

where $N u_{\mathrm{o}}$ is the asymptotic value for low Reynolds numbers. For spherical particles, using the diameter as characteristic length, the theoretical lower limit is 2 (Bennet \& Myers, 1988). For other geometries, zero values have been used (see Table 1). The maximum value reported (22.7) was obtained by Zuritz \& Sastry (1987). Exponents of the Reynolds $(b)$ and Prandtl $(c)$ numbers of 0.5 and 0.33 have been widely suggested in the classical literature. Published values of the Reynoldsnumber exponent range from 0.2 to 1.6 , with most between 0.43 and 0.67 . For the 


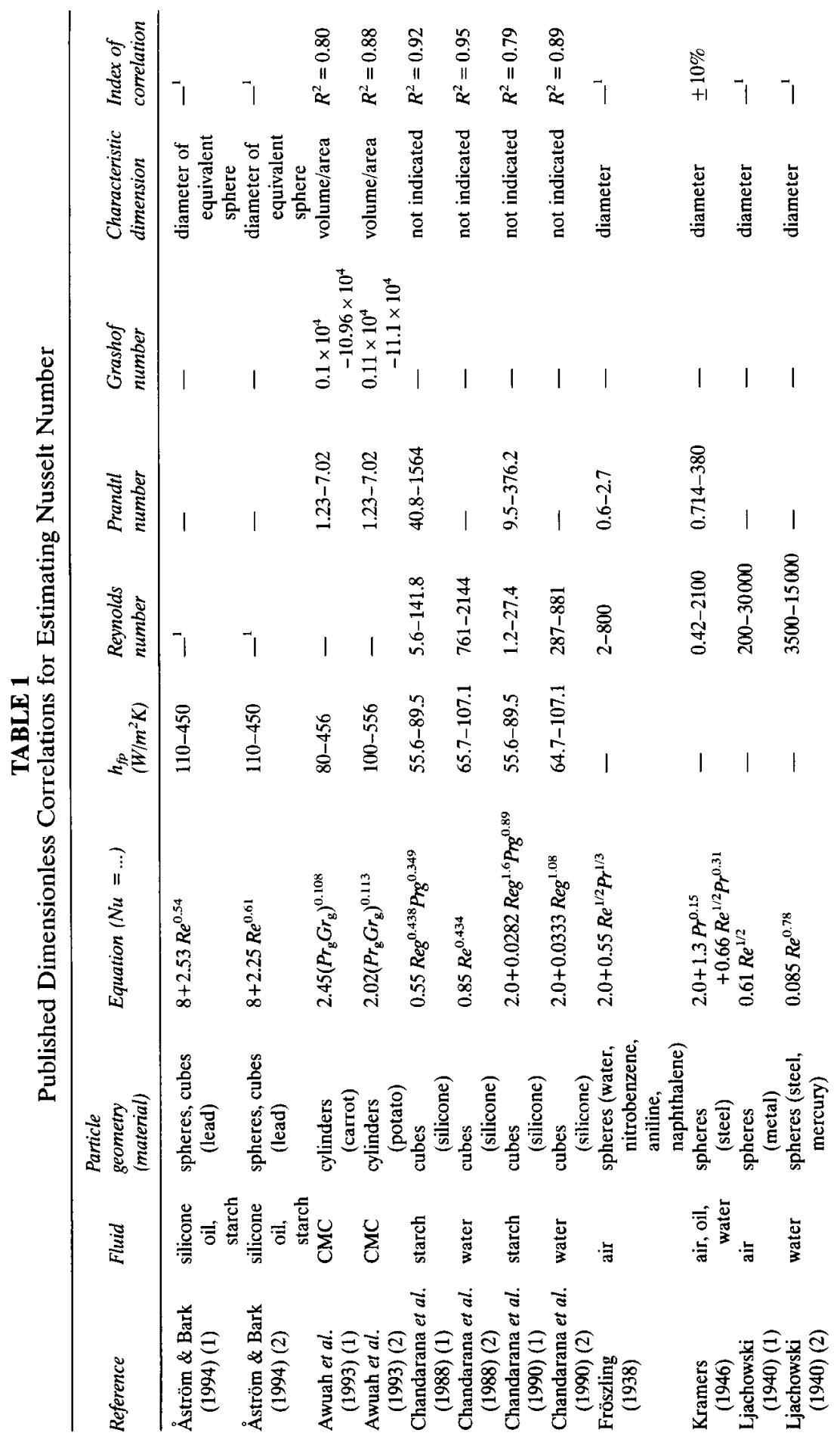




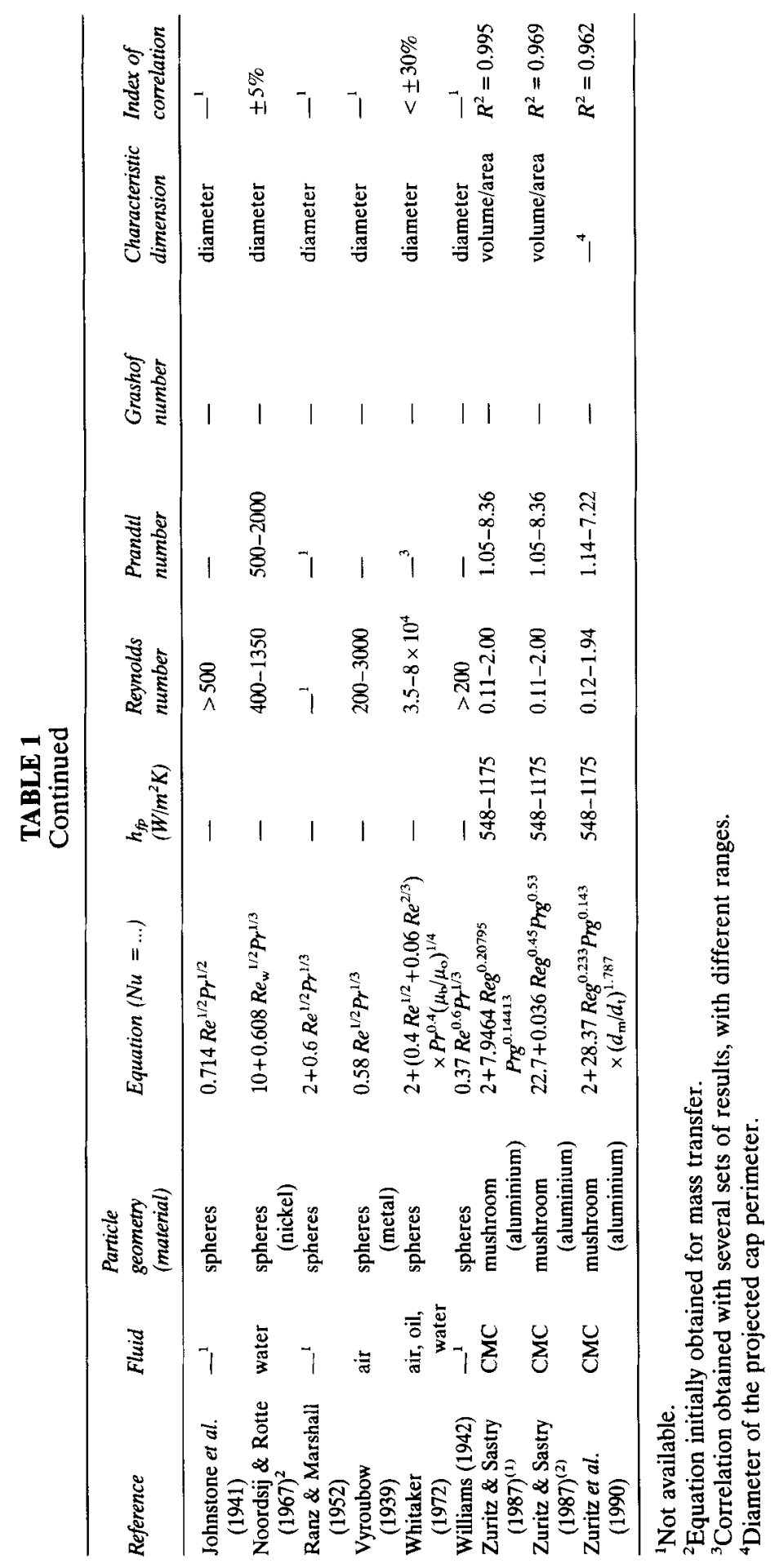


Prandtl-number exponent, values range from 0.143 to 0.89 , but 0.33 is the value suggested more frequently by researchers.

There are very few studies dealing with rotating particles. Åström \& Bark (1994) developed dimensionless correlations for still particles immersed in a liquid bath with walls rotating at different speeds. The particles were positioned at different increasing radial positions to simulate different conditions that, according to these authors, are usually found in particulate fluid flow: pure rotation in liquid at rest, eccentric rotation and mainly translation. Noordsij \& Rotte (1967) analysed the mass transfer process for rotating spheres, which can be considered for comparison as well, given the well-established dynamic similarity principles between convective heat and mass transfer. The results obtained in these two works are also summarized in Table 1.

It can be seen that there are many discrepancies in published studies and therefore there is a need for generalized approaches, essential if the research work is to have an industrial impact. It is also necessary to analyze both the case of a fluid moving around a particle and of a particle rotating in a fluid and their combination (the free movement of a particle in a carrier fluid). Situations of interest to food processing usually involve low Reynolds numbers, since the carrier fluid often is a viscous solution (e.g. sauce, syrup).

The purpose of this work was to study film heat transfer coefficients between solid particles and fluid, involving a wide range of Reynolds and Prandtl numbers, using fluids with different rheological properties, particles with different diameters, and different fluid average velocities and particle rotational velocities. The objectives were to compare experimental data obtained both for still particles immersed in a moving fluid and for particles rotating in an otherwise stagnant fluid with existing dimensionless correlations, to examine whether the two situations could be compared, and to develop further generalized dimensionless correlations, if necessary.

\section{MATERIALS AND METHODS}

\section{Particles and fluid}

Hollow spheres of aluminium alloy $6061-\mathrm{T} 6561\left(k_{\mathrm{p}, 25^{\circ} \mathrm{C}}=180 \mathrm{~W} / \mathrm{m} \mathrm{K} ; C_{p \mathrm{p}, 20^{\circ} \mathrm{C}}=\right.$ $896 \mathrm{~J} / \mathrm{kg} \mathrm{K} ; \rho_{\mathrm{p}}=2.70 \mathrm{~kg} / \mathrm{dm}^{3}$ (ASM, 1979)) with different diameters were used. A Teflon-insulated fine gauge copper-constantan thermocouple (TT-T-36, OMEGA, Stanford, CT) was soldered to the inner wall of the particle with a small amount of a solder with $83 \%$ cadmium and $17 \%$ zinc (Alsolder). A thin copper wire (diameter $=1 \mathrm{~mm}$ ) was also fixed together with the thermocouple, using an epoxy glue.

Non-Newtonian sodium carboxymethylcellulose solutions (CMC-70-G, Aqualon Co., Wilmington, DE) were used as the liquid phase. The CMC powder was slowly added to water at $45^{\circ} \mathrm{C}$ with continuous stirring for at least $2 \mathrm{~h}$, until complete dissolution. The fluid behaviour fitted well an Ostwald-de Waele (power law) equation. The consistency coefficient $(K)$ and flow behaviour index $(n)$ of the solutions were determined in a coaxial cylinder viscometer (Rheomat Model 115, Contraves Industrial Division, Cincinnati, $\mathrm{OH}$ ). Rheological measurements were performed at the beginning, in the middle and at the end of each set of experiments and no timedependent effects were found. Table 2 shows the rheological parameters obtained for the $\mathrm{CMC}$ solutions used, at $45^{\circ} \mathrm{C}$. This table also includes the intrinsic viscosity 
TABLE 2

Rheological Parameters of the Carboxymethylcellulose (CMC) Solutions at $45^{\circ} \mathrm{C}$

\begin{tabular}{cccc}
\hline & $\begin{array}{c}K^{l} \\
\text { Consistency } \\
\text { index } \\
\left(P a s^{n}\right)\end{array}$ & $\begin{array}{c}n^{l} \\
\text { Flow } \\
\text { behaviour } \\
\text { index }\end{array}$ & $\begin{array}{c}\mu_{s} \\
(\mathrm{~kg} / \mathrm{m} \mathrm{s})\end{array}$ \\
\hline 0.10 & $0.32 \pm 0.002$ & $0.75 \pm 0.03$ & $0.0103 \pm 0.0004$ \\
0.20 & $0.10 \pm 0.01$ & $0.69 \pm 0.02$ & $0.027 \pm 0.004$ \\
0.40 & $0.50 \pm 0.03$ & $0.59 \pm 0.01$ & $0.085 \pm 0.005$ \\
0.60 & $1.06 \pm 0.06$ & $0.55 \pm 0.01$ & $0.163 \pm 0.012$ \\
\hline
\end{tabular}

'Ostwald-de Waele equation: $\tau=k \gamma^{n}$.

$\left(\mu_{\mathrm{s}}\right)$, evaluated as the tangent of the shear stress $(\tau)$ versus shear rate $(\gamma)$ curve, for zero shear stress:

$$
\mu_{\mathrm{s}}=\lim _{\gamma \rightarrow 0}(\tau / \gamma)
$$

The density of CMC solutions was $1.00 \pm 0.01 \mathrm{~g} / \mathrm{cm}^{3}$, being independent of CMC concentration in the range used. The thermal conductivity and specific heat capacity of the solutions were determined using the correlations proposed by Heldman \& Singh (1981):

$$
\begin{gathered}
k_{\mathrm{f}}=\left[326.575+1.0412 T_{\mathrm{f}}-0.00337 T_{\mathrm{f}}^{2}\right] \cdot[0.796+0.009346 \mathrm{~W}] \times 10^{-3} \\
C_{p \mathfrak{t}}=1.675+0.025 \mathrm{~W}
\end{gathered}
$$

where $W$ is the percentage water content. The values of the physical properties of the system used in the calculation of the dimensionless numbers were at the temperature of the bulk fluid, that is, $45^{\circ} \mathrm{C}$. The particle and the boundary layer around it will be initially at a much lower temperature and evolve with time to the bulk fluid temperature. These values are therefore equilibrium reference values, which are used because it is not possible to account for the time dependence with dimensionless analysis.

\section{Experimental set-up}

Still particles immersed in a moving fluid

The experimental system used is schematically represented in Fig. 1. The CMC solution was prepared in the stirred jacket feed tank (FT) with temperature control, set to $45^{\circ} \mathrm{C}$. The temperature was maintained by automatic control of a steam-water mix. The solution was pumped to the tubular section with a positive displacement lobe pump (Waukesha Sanitary Pump size 25, Waukesha Foundry Co., Waukesha, WI) (P) and recycled to the tank. Individual particles were introduced rapidly at the entry section (ES) and placed at the bottom of the tube. This position was chosen because it would subject the particle to the largest variability in the fluid's incoming velocity profile. The entry section, a transparent $T$-tube with an internal diameter of $5.08 \mathrm{~cm}$, was attached to the main section, a straight transparent tube (MS) $1.5 \mathrm{~m}$ long and inclined at $1.19^{\circ}$. The flow rate was measured by a magnetic flowmeter (Model 8712 CR12M4, Rosemount, Eden Prairie, MN) (FM). The temperature at the inlet of the transparent section, the particle temperature and the flow rate were 


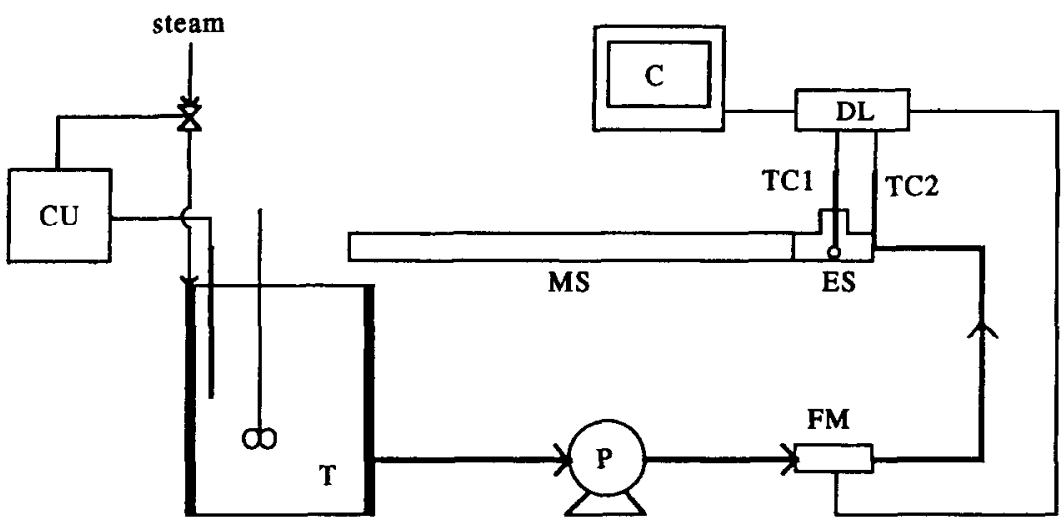

Fig. 1. Experimental set-up for determination of fluid-to-particle heat transfer coefficients for still particles immersed in a moving fluid. T, stirred jacket tank; CU, control unit; P, pump; ES, entry section; MS, main section; FM, flowmeter; TC1, TC2, thermocouples; C, computer; DL, data logger.

continuously monitored with a personal computer (data acquisition time $0.2 \mathrm{~s}$ ) linked to a data logger (21X Micrologger, Campbell Scientific Inc., Logan, UT) (DL). The acquisition was stopped when the temperature difference between the fluid and the particle was $<2^{\circ} \mathrm{C}$.

Particles rotating in an otherwise stagnant fluid

The experimental set-up is schematically represented in Fig. 2. A particle (P) was attached to a motor $(\mathrm{M})$ with thin copper wire $(\mathrm{W})$ and introduced into a $150 \mathrm{~mm}$

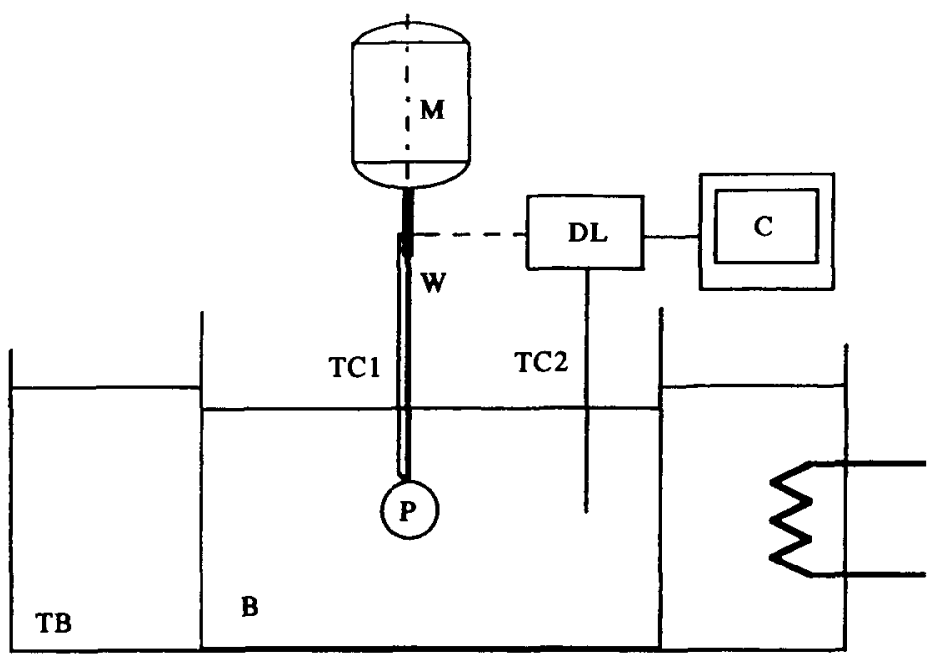

Fig. 2. Experimental set-up for determination of fluid-to-particle heat transfer coefficients for particles rotating in an otherwise stagnant fluid. $\mathrm{P}$, particle; $\mathrm{M}$, motor; $\mathrm{W}$, wire; $\mathrm{B}$, beaker; TB, thermostatic bath; TC1, TC2, thermocouples; C, computer; DL, data logger. 
diameter beaker (B) containing a $\mathrm{CMC}$ solution. This beaker was immersed in a thermostatic stirred bath (TB) at $45^{\circ} \mathrm{C}$. The motor was immediately switched on after introducing the particle into the CMC solution and the temperature of the solution and the particle temperature were continuously monitored as above.

\section{The experiments}

For the still particles immersed in a moving fluid, a total of 112 experiments were carried out, corresponding to all combinations of four fluid viscosities (Table 2), four particle diameters $(1.27,1.59,1.91$ and $2.23 \mathrm{~mm}$ ) and seven flow rates (average fluid velocity: $0,0.062,0.093,0.124,0.187,0.249,0.311 \mathrm{~m} / \mathrm{s}$ ). For the rotating particles, an equal number of experiments (112) were performed at the same conditions, with the seven flow rates replaced by seven rotational velocities of the particle $(0,8.1,24.3,64.4,96.8,193.7,291.5 \mathrm{rev} / \mathrm{s})$. For each experiment, at least four replicates were performed.

Particles were always previously cooled to $0-1^{\circ} \mathrm{C}$.

\section{Theoretical considerations}

The fluid-to-particle heat transfer coefficient can be calculated based on equations developed from an overall energy balance under transient conditions. When the internal resistance to heat transfer is small compared with the resistance due to convection at the particle surface, the temperature gradient inside the particle is negligible (situation known as lumped capacity method or Newtonian heating). That condition is verified by the Biot number $\left(B i=h_{\mathrm{fp}} L / k_{\mathrm{p}}\right)$, which must be $<0.1$ (Brodkey \& Hershey, 1988). Under these simplified conditions, the temperature history is described by:

$$
\ln \left[\frac{T-T_{\mathrm{f}}}{T_{\mathrm{i}}-T_{\mathrm{f}}}\right]=\left(\frac{h_{\mathrm{fp}} A_{\mathrm{p}}}{m_{\mathrm{p}} C_{p \mathrm{p}}}\right) t
$$

where $T_{\mathrm{f}}, T_{\mathrm{i}}$ and $T$ are, respectively, the temperature of the fluid, the particle initial temperature and the particle temperature at time $t ; A_{\mathrm{p}}, m_{\mathrm{p}}$ and $C_{p \mathrm{p}}$ are, respectively, the surface area, the mass and the specific heat capacity of the particle.

\section{Data analysis}

Biot numbers between 0.0005 and 0.021 were obtained, establishing the validity of the Newtonian heating assumption. The fluid-to-particle heat transfer coefficient was obtained by linear regression, according to eqn (5).

The Nusselt number $\left(N u=h_{\mathrm{fp}} d_{\mathrm{p}} / k_{\mathrm{f}}\right)$ was then calculated and correlated with the appropriate generalized dimensionless numbers, also calculated from the data and operating conditions. For stagnant conditions, that is, when both fluid and particles were still, correlations were based on the Prandtl and Grashof numbers, since in these conditions only natural convection occurs. The intrinsic viscosity was used in the calculations: 


$$
\begin{gathered}
\operatorname{Pr}_{\mathrm{s}}=C_{p \mathrm{f}} \frac{\mu_{\mathrm{s}}}{k_{\mathrm{f}}} \\
G r=\frac{d_{\mathrm{p}}^{3} g \beta \rho_{\mathrm{f}}^{2}\left(\frac{T_{\mathrm{av}}-T_{\mathrm{f}}}{2}\right)}{\mu_{\mathrm{s}}^{2}}
\end{gathered}
$$

where $d_{\mathrm{p}}$ is the particle diameter, $T_{\mathrm{av}}$ the average particle temperature during the experiment, $g$ the acceleration of gravity and $\beta$ the expansion coefficient, which was assumed to be that of water in similar conditions.For the other situations, where either the fluid or the particles were moving, the generalized Prandtl $\left(\operatorname{Pr}_{\mathrm{g}}\right)$ and Reynolds $\left(R e_{\mathrm{g}}\right)$ numbers defined by Skelland (1967) for spherical particles and power-law fluids were used:

$$
\begin{gathered}
\operatorname{Pr}_{\mathrm{g}}=\frac{C_{p \mathrm{f}} K\left(\frac{3 n+1}{n}\right)^{n} 2^{n-3}}{k_{\mathrm{f}}\left(\frac{V_{\mathrm{r}}}{d_{\mathrm{p}}}\right)^{1-n}} \\
\operatorname{Re}_{\mathrm{g}}=\frac{8 \rho_{\mathrm{f}} v_{\mathrm{r}}^{2-n} d_{\mathrm{p}}^{n}}{2^{n} \mathrm{~K}\left(\frac{3 n+1}{n}\right)^{n}}
\end{gathered}
$$

where $v_{\mathrm{r}}$ represents the average relative velocity between the fluid and the particle, that is, the fluid velocity $\left(v_{\mathrm{f}}\right)$ for the immobilized particles, and the maximum linear velocity of the particle surface $\left(v_{\omega}=\omega \pi \mathrm{d}_{\mathrm{p}}, \omega\right.$ being the rotational velocity in rev/s) for rotating particles. It is important to note that $R e$ for a rotational movement is considered in some literature without the constant $\pi$. When comparisons are made, values referred in this text were always converted to the definition used here, when necessary.

\section{RESULTS AND DISCUSSION}

\section{Analysis of published correlations}

Reynolds numbers between 4.1 and 636 were obtained for the still particles and between 0.1 and 801 for the rotating particles. For a spherical particle immersed in a fluid (no radial velocity gradicnt bcfore encountering the particle), laminar flow will occur for Reynolds numbers below 2 and transition regime will then take place up to $R e<500$ (Brodkey \& Hershey, 1988). Although this situation is slightly different from the one created in this work, where the particles werc placed at the bottom of a tube, facing a marked velocity profile of the incoming fluid, it is apparent that most results for the still particles were obtained in the transient 
regime, with the possibility of turbulent regime for the higher Reynolds numbers. For rotating particles, flow conditions are not well studied and limiting Reynolds numbers for the laminar regime could not be found in the literature. For rotating paddles an $R e$ limit of 30 has been reported (Brodkey \& Hershey, 1988). However, because the spherical geometry is less likely to cause turbulence than the paddles, the limiting Reynolds number may well be above that value. Nevertheless, since the maximum Reynolds number in this case was 801 , it is likely that experiments were performed in both laminar and transition regimes. It was however decided to fit all results together, bearing in mind this fact, in case a different pattern would occur for the higher Reynolds numbers. Prandtl numbers between 69 and 1810 were obtained for the still particles and between 71 and 5340 for the rotating particles. Average heat transfer coefficients ranged between 56 and $2612 \mathrm{~W} / \mathrm{m}^{2} \mathrm{~K}$ for the still particles and between 67 and $1782 \mathrm{~W} / \mathrm{m}^{2} \mathrm{~K}$ for the rotating particles, the Nusselt numbers being respectively between 9.0 and 88.3 and between 2.5 and 60.7 .

Figure 3 shows the relation between the experimental Nusselt numbers obtained for the still particles and the values predicted by the correlations shown in Table 1. Unfortunately, the range of Reynolds and Prandtl numbers of the correlations mentioned in Table 1 is quite diverse and many experimental conditions fall outside their range of validity. However, results are shown for all cases, extrapolating the published correlations when necessary. Points shown as solid symbols were obtained inside the validity range of the corresponding correlation, while open symbols indicate those obtained outside the region of validity of either the Prandtl or the Reynolds number. It is interesting to note that there is no observed discontinuity in the comparisons between experimental and predicted values depending on whether the correlation was used inside the region of validity or not.

Figure 3(A) shows the results for correlations developed by Zuritz \& Sastry (1987), Zuritz et al. (1990) and Chandarana et al. (1988). All the models of Zuritz \& Sastry (1987) and Zuritz et al. (1990) were obtained for very low Reynolds numbers and the extrapolations predicted a much less pronounced variation of the Nusselt number than the one verified in this work. The correlation of Chandarana et al. (1988) also shows this pattern, underestimating the experimental values, except for low $\mathrm{Nu}$ numbers $(<20)$, where good agreement was found. The correlation suggested by Chandarana et al. (1990) was not even considered, because the predicted $\mathrm{Nu}$ values, between 98 and 23782, were too high. Overall, it can be concluded that these correlations did not provide a good prediction of the behaviour observed.

Figure 3(B) and (C) show the results estimated with other correlations. Table 3 shows the coefficient of variation for these correlations. Overall it can be concluded that these models provide a much better fit to the experimental results, even when the predictions come from extrapolation outside the range of validity. The models of Kramers (1946) and Vyroubow (1939) give similar results inside their range of validity that are reasonable estimates up to a Nusselt number around 60 , underpredicting from then on. All models in Fig. 3(B) also predict a smaller variation of the Nusselt number than the one obtained experimentally in this work, although not as much as those in Fig. 3(A). The models in Fig. 3(C) provide for a similar pattern of variation of the Nusselt number. The correlation of Williams (1942) gives the best results, even when used outside its range of validity (coefficient of variation 12.3), although underpredicting slightly the experimental results for higher Nusselt numbers $(N u>60)$. The Johnstone et al. (1941) model was not plotted, because the predicted $\mathrm{Nu}$ values, between 50 and 165 , were too high. 


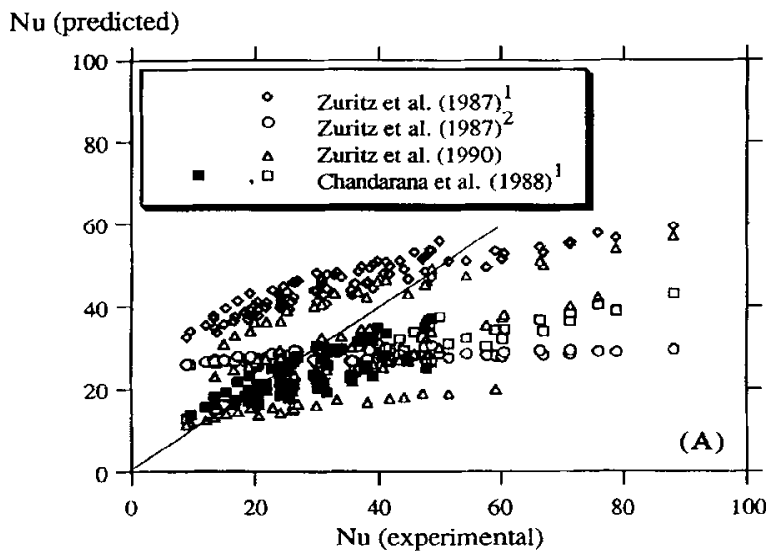

Nu (predicted)

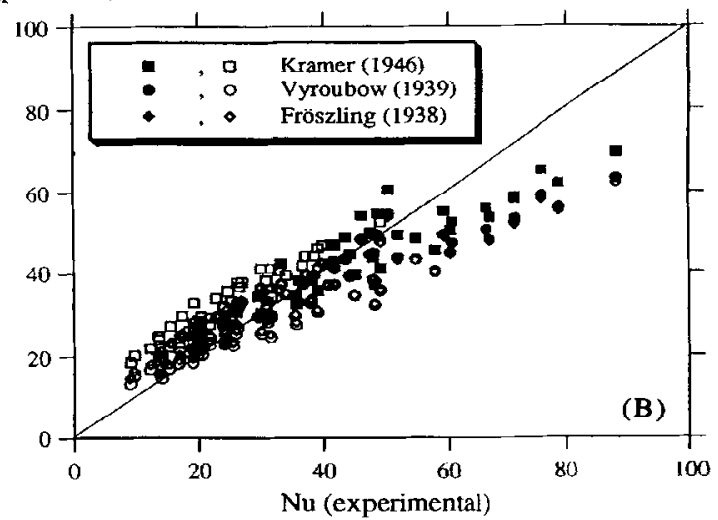

Nu (predicted)

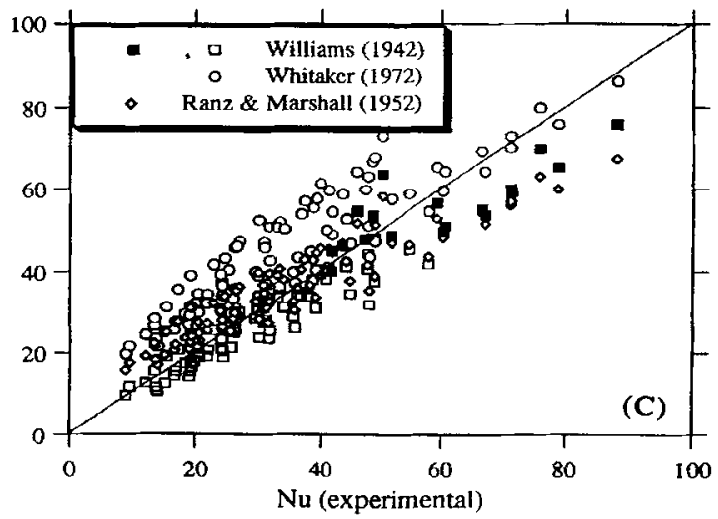

Fig. 3. Comparison between experimental results for still particles immersed in a moving fluid and predictions using models developed: (A) Zuritz \& Sastry (1987); Zuritz et al. (1990); Chandarana et al. (1988); (B) Kramers (1946); Vyroubow (1939); Fröszling (1938); (C) Williams (1942); Ranz \& Marshall (1952); Whitaker (1972). Open symbols represent predictions made outside the range of validity of the respective model: see Table 1 . 
TABLE 3

Coefficient of Variation Between Experimental Nusselt Numbers for Still Particles Immersed in a Moving Fluid and Values Predicted Using Dimensionless Correlations Published in the Chemical Engineering Field

\begin{tabular}{lc}
\hline Correlation & $\begin{array}{c}\text { Coefficient of } \\
\text { variation }\end{array}$ \\
\hline Fröszling (1938) & 17.3 \\
Kramers (1946) & 26.4 \\
Ranz \& Marshall (1952) & 21.0 \\
Whitaker (1972) & 42.3 \\
Williams (1942) & 12.3 \\
Vyroubow (1939) & 15.6 \\
\hline
\end{tabular}

Figure 4 shows the results obtained for the rotating particles. The only correlation that could be tried, obtained by Noordsij \& Rotte (1967) for mass transfer and rewritten for heat transfer, was outside the range of validity, mainly because the Prandtl number range is too high. It is interesting to note that extrapolation to the range of the experimental results in this work would overpredict the Nusselt number, but suggests a similar dependence of $\mathrm{Nu}$ on the Reynolds and Prandtl numbers.

\section{Non-dimensional correlations for stagnant conditions}

The asymptotic value of $N u$ when $R e$ decreases to zero is one of the more interesting differences between the different models. For stagnant situations, fluid-to-

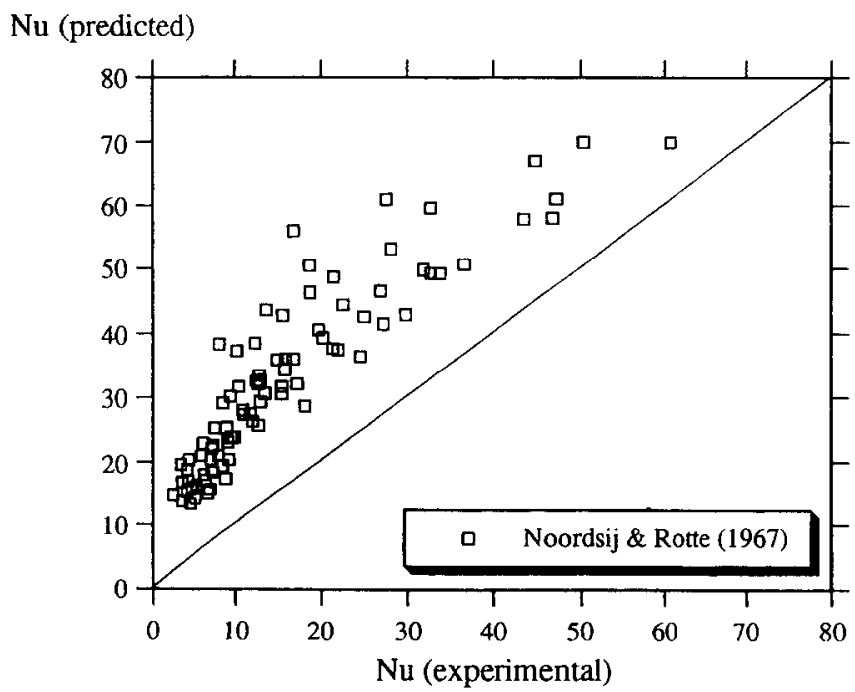

Fig. 4. Comparison between experimental results for particles rotating in an otherwise stagnant fluid and prediction using the model developed by Noordsij \& Rotte (1967). All predictions are made outside the range of validity of the model: see Table 1. 
particle heat transfer coefficients between 56 and $203 \mathrm{~W} / \mathrm{m}^{2} \mathrm{~K}$ were obtained, covering a range of Nusselt numbers between 2 and 7.8. These results clearly show that even for these limit conditions, assumption of the theoretical value of 2 for the Nusselt number may lead to underestimation of the heat transfer coefficients, depending on the fluid characteristics. This is probably due to neglecting natural convection. The real limit for stagnant conditions is not 2 , since this is the value for pure conduction. An equation of the type

$$
N u_{\mathrm{o}}=2+h \operatorname{Pr}_{\mathrm{s}}^{i} G r^{j}
$$

is often used in the literature to correlate data obtained for natural convection heat transfer for Newtonian fluids (Brodkey \& Hershey, 1988). Because we were dealing with non-Newtonian fluids, Prandtl and Grashof numbers evaluated with the intrinsic viscosity [eqns (6) and (7)] were used. Considering that a limited number of experiments were performed ( 32 experiments, each with four replicates) and that the effect of $P r_{\mathrm{s}}$ and $G r$ would be assessed properly only by the use of different fluid viscosities and different particle diameters, an accurate determination of the three coefficients in eqn (10) would not be feasible. Therefore, the coefficients $i$ and $j$ were considered to be respectively $1 / 3$ and $1 / 2$ (Fröszling, 1938), the values usually found in the literature for this type of correlation. The coefficient $h$ was optimized by linear regression, resulting in the following dimensionless correlation:

$$
N u_{\mathrm{s}}=2+(0.025 \pm 0.004) \operatorname{Pr}_{\mathrm{s}}^{1 / 3} G r^{1 / 2}
$$

for $72.6<P r_{\mathrm{s}}<1287.4$ and $2.8<G r<4840$. Figure 5 shows the good agreement between the values predicted by this equation and the experimental data (correlation coefficient 0.93 ).

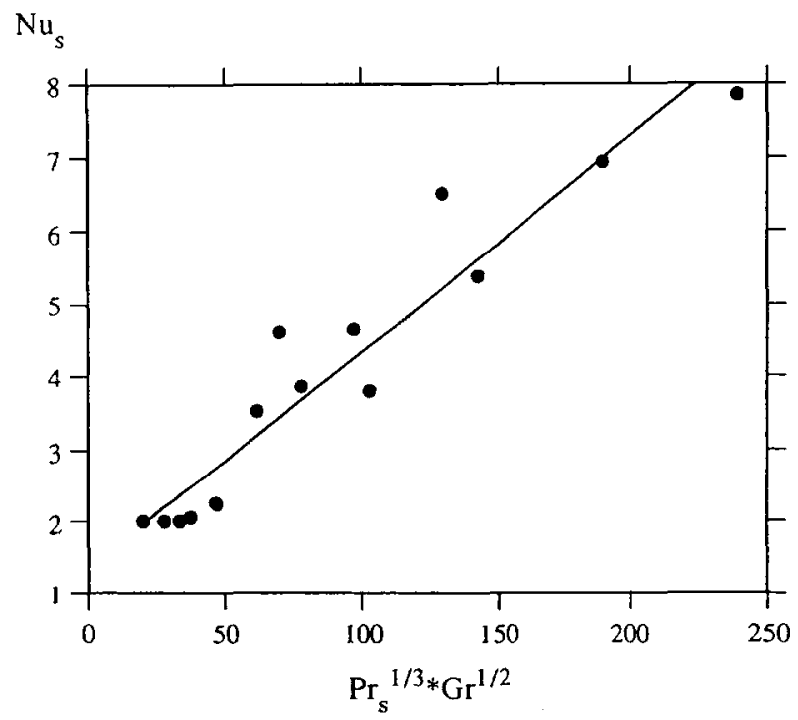

Fig. 5. Variation of the Nusselt number with the Prandtl and Grashof numbers under stagnant conditions, due to the existence of natural convection. 


\section{Fröszling-type correlation of the experimental results}

A new correlation was developed, specifically for the results in this work, using the Fröszling-type equation and considering the asymptotic value for $\mathrm{Nu}$ given by eqn (11):

$$
N u=N u_{\mathrm{s}}+a \operatorname{Re}_{\mathrm{g}}^{b} P r_{\mathrm{g}}^{c}
$$

The parameters $a, b$ and $c$ were determined by multilinear regression with the logarithmic form of eqn (12), using the STATA software (Stata 3.0, Computing Resource Center, 1992). Results for still and rotating particles were analysed independently.

Still particles in a moving fluid:

$$
N u=N u_{\mathrm{s}}+(0.20 \pm 0.06) R e_{\mathrm{g}}^{(0.67 \pm 0.03)} \operatorname{Pr}_{\mathrm{g}}^{(0.38 \pm 0.03)}
$$

with a correlation coefficient of 0.960 .

Rotating particles in an otherwise stagnant fluid:

$$
N u=N u_{\mathrm{s}}+(0.081 \pm 0.04) \operatorname{Re}_{\mathrm{g}}^{(0.70 \pm 0.04)} \operatorname{Pr}_{\mathrm{g}}^{(0.42 \pm 0.06)}
$$

with a correlation coefficient of 0.916. The results are shown in Figs 6 and 7. It can be seen that the exponents of $R e$ and $P r$ were statistically identical in the two situations, the only difference being the coefficient $a$, the value for the still particles being 2.5 times that for rotating particles. In both cases this coefficient was clearly lower than that suggested by Fröszling (1938), while the Prandtl and Reynolds exponents were higher, particularly for the rotating particles. It is also clear that a better fit was obtained for the still particles, which is due to the higher scatter of the experimental data obtained for the rotating particles and not to a systematic deviation. No significant difference arising from the different flow regimes was observed.

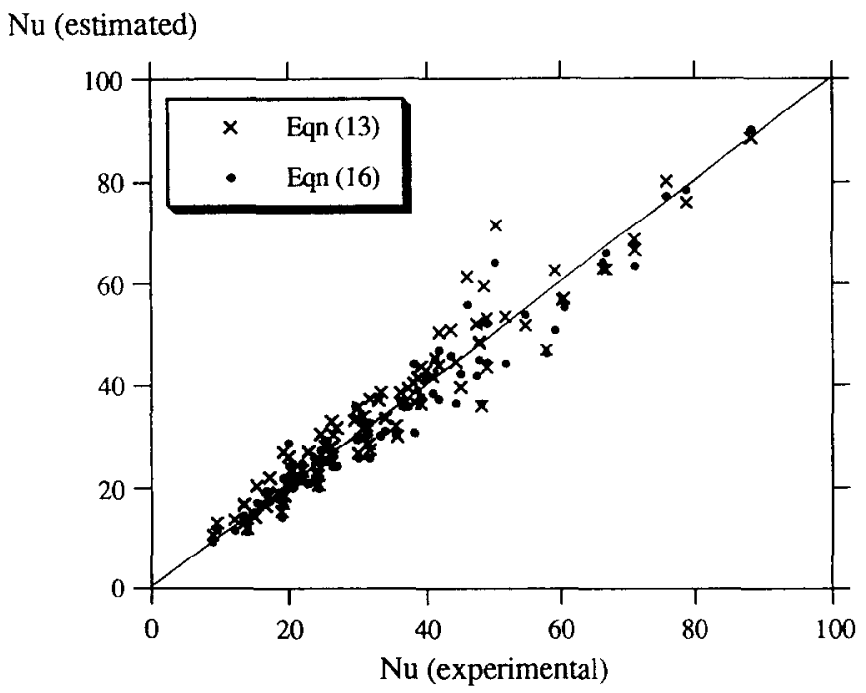

Fig. 6. Analysis of the fit between the experimental results for still particles immersed in a moving fluid and the models propsed in this work. 


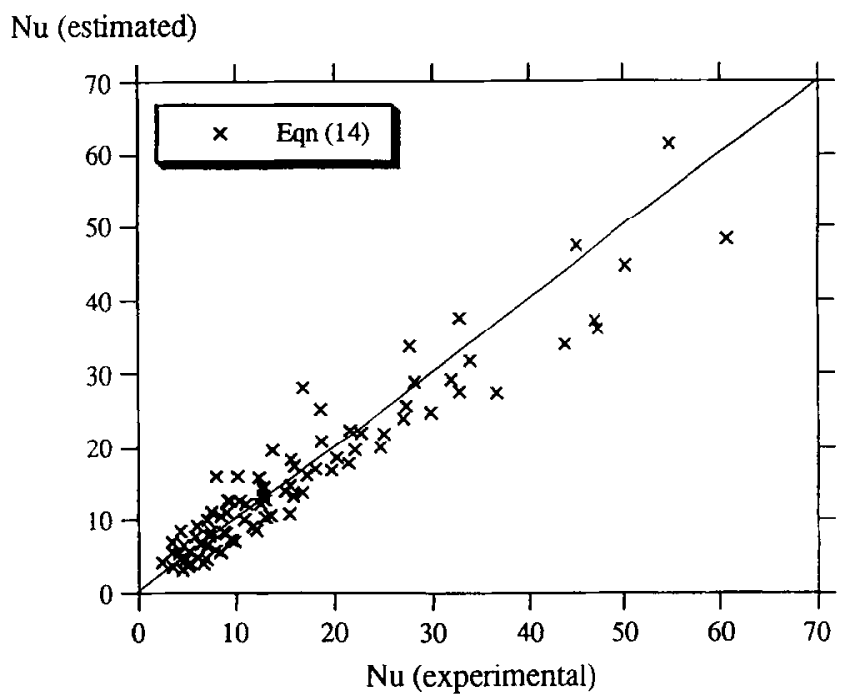

Fig. 7. Analysis of the fit between the experimental results for particles rotating in an otherwise stagnant fluid and the model proposed in this work [eqn (14)].

The Fröszling equation was developed for a spherical particle immersed in an infinite fluid, that is, for a flat velocity profile, except around the particle region. In the present situation, the fluid has a significant velocity profile due to the proximity of the tube walls. It can therefore be expected that particles with different diameters are actually subjected to different average fluid velocities and might therefore be subject to different hydrodynamic conditions, affecting the heat transfer process. Since the particles were placed at the bottom of the tube, larger particles would be subjected to higher average fluid velocities and should have an improved heat transfer rate. Therefore, another dimensionless correlation was considered, identical to eqn (13), but where the Reynolds and Prandtl numbers were evaluated in terms of the average velocity of the undisturbed fluid in the projected area of the particle $\left(v_{\mathrm{fp}}\right)$, instead of the whole cross-flow area. It can be easily shown that this average velocity may be expressed as:

$$
v_{\mathrm{fp}}=v_{\mathrm{o}}\left[1-\frac{1}{2}\left(\frac{r_{\mathrm{p}}}{R_{\mathrm{t}}}\right)^{2}-\frac{8}{3 \pi} \frac{R_{\mathrm{o}} r_{\mathrm{p}}}{R_{\mathrm{t}}^{2}}-\left(\frac{R_{\mathrm{o}}}{R_{\mathrm{t}}}\right)^{2}\right]
$$

where $v_{\mathrm{o}}$ is the fluid velocity at the central position, $r_{\mathrm{p}}$ the particle radius, $R_{\mathrm{t}}$ the tube radius and $R_{\mathrm{o}}$ the distance between tube and particle centre. The following correlation was then obtained:

$$
N u=N u_{\mathrm{s}}+(0.64 \pm 0.15) R e_{\mathrm{g}}^{(0.59 \pm 0.02)} \operatorname{Pr}_{\mathrm{g}}^{(0.28 \pm 0.03)}
$$

with a correlation coefficient of 0.967 . The fit obtained is also shown in Fig. 6 . It is curious to note that although the coefficient of variation docs not reflect a significant improvement, despite the higher correlation coefficient, the exponents of $R e$ and $\operatorname{Pr}$ are now closer to those of the Fröszling equation. 
It can be similarly argued that the heat transfer rate for the rotating particle should not be controlled by the rotational velocity alone: an effect of the velocity profile around the particle, being more or less pronounced depending on the proximity of the walls, should be visible as well. When the distance to the wall is very large, its presence is negligible and an infinite medium can be considered. In those conditions, in the laminar regime the fluid-to-particle relative velocity approaches zero, that is, $\mathrm{Nu}$ should approach $N u_{\mathrm{s}}$ as the velocity decreases. This was in fact observed by Åström \& Bark (1994) for a similar situation, in which a $16 \mathrm{~mm}$ spherical particle was immersed in the centre of a fluid contained in a $200 \mathrm{~mm}$ diameter rotating vessel. This effect of increasing the ratio between the container and the particle diameter follows a similar reasoning to what is expected for still particles in a moving fluid. If the particle is very small compared with the tubc diameter, the fluid velocity at the particle location (assuming a stationary flow) should become equal to the local fluid velocity. The particle is located at the bottom of the tube and therefore the local fluid velocity should approach zero. This conclusion may also be drawn from eqn (15), which also shows that this effect is increasingly important with increasing average fluid velocities (Fig. 8). Then, the difference between the correlations for still and rotating particles may have been due simply to a different ratio of particle diameter to tube or container diameter. Therefore a new correlation was tested, similar to eqn (12), but including a correction term accounting for the effect of $d_{\mathrm{p}} / d_{\mathrm{t}}$ :

$$
N u=N u_{\mathrm{s}}+a \operatorname{Re}_{\mathrm{g}}^{b} \operatorname{Pr}_{\mathrm{g}}^{c}\left(d_{\mathrm{p}} / d_{\mathrm{t}}\right)^{d}
$$

This equation was correlated to all the data, yielding:

$$
N u=N u_{\mathrm{s}}+(0.17 \pm 0.06) R e_{\mathrm{g}}^{(0.71 \pm 0.03)} \operatorname{Pr}_{\mathrm{g}}^{(0.42 \pm 0.04)}\left(d_{\mathrm{p}} / d_{\mathrm{t}}\right)^{(0.28 \pm 0.05)}
$$

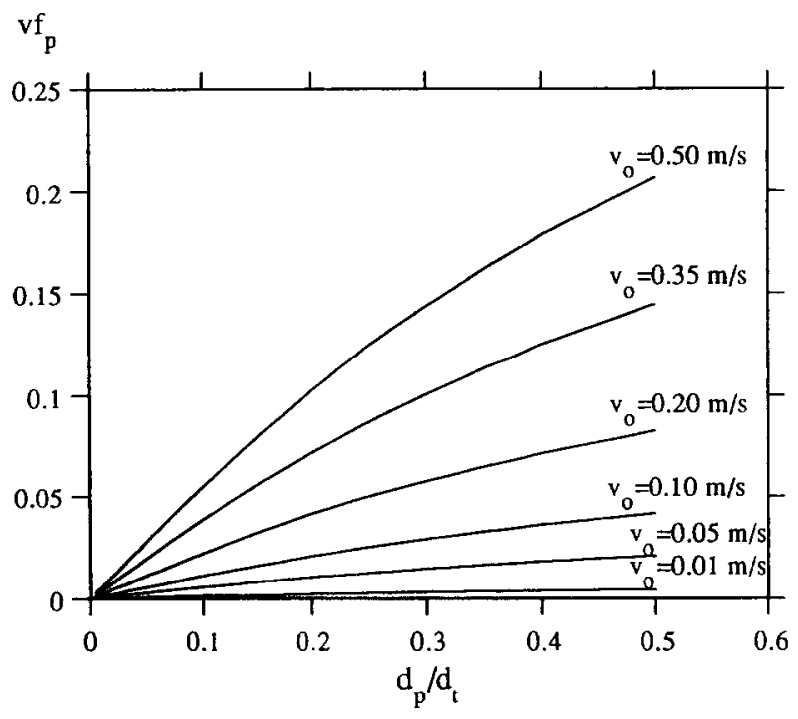

Fig. 8. Effect of the particle/tube diameter ratio on the average fluid velocity in the projected area of the particle, for different flow rates. 


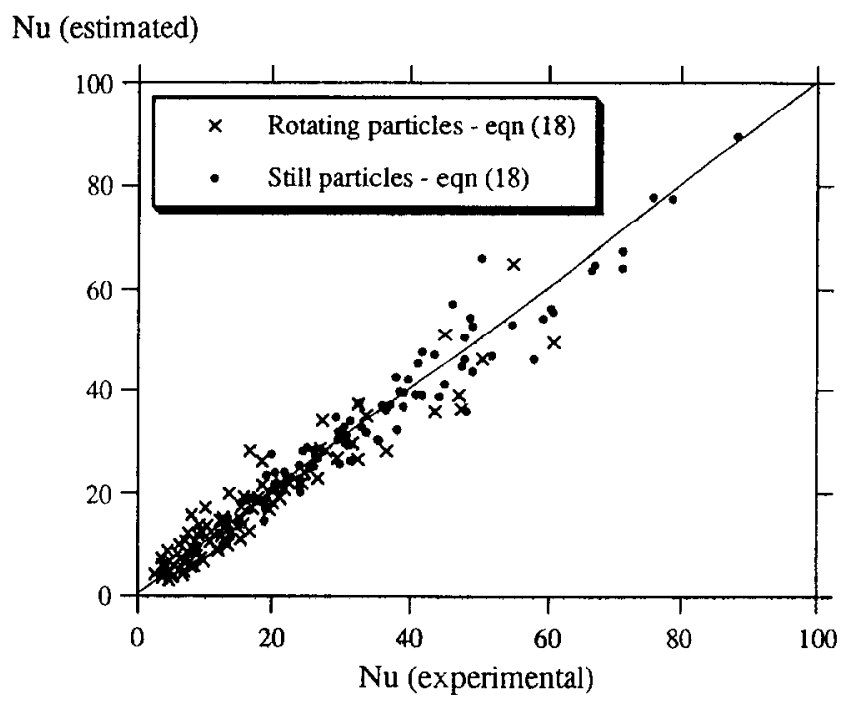

Fig. 9. Analysis of the fit between all experimental results and the generalized model proposed in this work [eqn (18)].

with a correlation coefficient of 0.955 . The good agreement is shown in Fig. 9. It should be emphasized that although this new correlation has the advantage of describing jointly the two situations, it is specific to the situations considered. If for instance the fixed particle were to be positioned at the centre of the tube, the effect of increasing the particle diameter would be expected to be exactly the opposite of that described by this correlation, while the equation based on the average fluid velocity in the position of the particle could be expected to give good results.

\section{CONCLUSIONS}

For still particles, values of average fluid-to-particle heat transfer coefficients between 56 and $2612 \mathrm{~W} / \mathrm{m}^{2} \mathrm{~K}$ were obtained, while for rotating particles lower values were obtained for similar conditions, 67 to $1782 \mathrm{~W} / \mathrm{m}^{2} \mathrm{~K}$. This difference was found to be due to the fact that the ratio of particle diameter to tube (recepacle) diameter was 2.5 times higher in the first situation, leading to different boundary layer conditions. On the basis of this assumption it was possible to obtain a single correlation for all the data, similar to a Fröszling-type equation, with an additional correction term to describe the effect of ratio of diameters. It should be noted that this equation is specific to the positions at which the particles were immersed: bottom position for still particles and central position for rotating particles. Other positions were not considered and further work would be required to develop more general equations. The asymptotic value used in the original Fröszling equation for low Rcynolds numbers (2) was considercd inadequate, as it was shown that in stagnant conditions, natural convection leads to higher heat transfer coefficients. This limit value was therefore replaced by a natural-convection-type correlation. 
It was also found that the experimental data were not well correlated by the equations published in the food engineering area, whereas classical correlations from the chemical engineering field provided better results.

\section{ACKNOWLEDGEMENTS}

The authors P. N. B., F. A. R. O. and J. C. O. are grateful to the Junta Nacional de Investigação Científica e Tecnológica and to the Commission of the European Communities (Flair Programme) for financial support. The authors would like to thank B. Heskitt for invaluable technical support.

\section{REFERENCES}

ASM (1979). Metals Handbook, Vol. 2, Properties and Selection: Nonferrous Alloys and Pure Metals. American Society for Metals, Metals Park, OH, pp. 115-116.

Åström, A. \& Bark, G. (1994). Heat transfer between fluid and particles in aseptic processing. J. Food Eng., 21, 97-125.

Awuah, G. B., Ramaswamy, H. S. \& Simpson, B. K. (1993). Surface heat transfer coefficients associated with heating of food particles in CMC solutions. J. Food Process Engng., 16, $39-57$.

Balasubramaniam, V. M. (1993). Liquid-to-particle convective heat transfer in aseptic processing systems. Ph.D. thesis, Ohio State University, Columbus, $\mathrm{OH}$.

Bennet, C. O. \& Myers, J. E. (1988). Momentum, Heat, and Mass Transfer. McGraw-Hill, Singapore, pp. 394-395.

Brodkey, R.S. \& Hershey, H.C. (1988). Transport Phenomena. McGraw-Hill, Singapore, p. 599.

Chandarana, D. I., Gavin, A. \& Wheaton, F. W. (1988). Particle/fluid interface heat transfer during aseptic processing of foods. ASAE Paper No. 88-6599.

Chandarana, D. I., Gavin, A. \& Wheaton, F. W. (1990). Particle/fluid interface heat transfer under UHT conditions at low particle/fluid relative velocities. J. Food Process Engng, 13, 191-206.

Dignan, D. M., Berry, M. R., Pflug, I. J. \& Gardine, T. D. (1989). Safety considerations in establishing aseptic processes for low-acid foods containing particulates. Food Technol., 43, 118-121.

Dutta, B. \& Sastry, S. K. (1990). Velocity distributions of food particles suspensions in holding tube flow: experimental and modeling studies on average particles velocities. $J$. Food Sci. 55, 1448-1453.

Dutta, B. \& Sastry, S. K. (1990). Velocity distributions of food particles suspensions in holding tube flow: characteristics and fastest-particle velocities. J. Food Sci., 55, 1703-1710.

Fröszling, N. (1938). Gerl. Beitr. Geophys., 52, 170 [Cited in Kramers (1946)].

Heldman, D. R. \& Singh, R. P. (1981). Food Process Engineering. AVI Publication Co., Westport, CT.

Johnstone, H.F., Pigford, R.L. \& Chapin, J.H. (1941). Heat transfer to clouds of falling particles, Trans. AIChE, 37, 95. [Cited in Chang, S.Y. \& Toledo, R.T. (1989). Heat transfer and simulated sterilization of particulate solids in a continuously flowing system. J. Food Sci., 54, 1017-23, 1030].

Kramers, H. (1946). Heat transfer from spheres to flowing media. Physica, 12, 61-80.

Ljachowski, D.N. (1940). J. Tech. Phys., Leningrad, 10, 999 [Cited in Kramers (1946)].

Maesmans, G., Hendrickx, M., DeCordt, S., Fransis, A. \& Tobback, P. (1992). Fluid-toparticle heat transfer coefficient determination of heterogeneous foods: a review. J. Food Process. Preserv., 16, 29-69. 
Mwangi, J. M., Rizvi, S. H. \& Datta, A. K. (1993). Heat transfer to particles in shear flow: application in aseptic processing. J. Food Engng., 19, 55-74.

Noordsij, P. \& Rotte, J. W. (1967). Mass transfer coefficients to a rotating and to a vibrating sphere. Chem. Engng. Sci., 22, 1475-1481.

Palmieri, L., Cacace, D., Dipollina, G. \& Dall'Aglio, G. (1992). Residence time distribution of food suspensions containing large particles when flowing in tubular systems. J. Food Engng., 17, 225-239.

Ranz, W. E. \& Marshall, W. R. (1952). Chem. Engng. Prog., 48, 141-146.

Sastry, S. K. \& Zuritz, C. A. (1987). A model for particle suspension flow in a tube. ASAE Paper No. 87-6537.

Skelland, A.H.P. (1967). Non-Newtonian Flow and Heat Transfer. Wiley, NY.

Vyroubow, D. (1939). J. Tech. Phys., Leningrad, 9, 1923 [Cited in Kramers (1946)].

Whitaker, S. (1972). Forced convection heat transfer correlations for flow in pipes, past flat plates, single cylinders, single spheres, and for flow in packed beds and tube bundles. AIChE J., 18, 361-371.

Williams, G.C. (1942). Sc.D. Thesis, Massachusetts Institute of Technology, Cambridge, MA [cited in Chang, S.Y. \& Toledo, R.T. (1989). Heat transfer and simulated sterilization of particulate solids in a continuously flowing system. J. Food Sci., 54, 1017-1023, 1030].

Zitoun, K.B. \& Sastry, S. K. (1994). Determination of convective heat transfer coefficient between fluid and cubic particles in continuous tube flow using noninvasive experimental techniques. J. Food Process Engng., 17, 209-228.

Zitoun, K. B. \& Sastry, S. K. (1994). Convective heat transfer coefficient for cubic particles in continuous tube flow using the moving thermocouple method. J. Food Process Engng., $17,229-241$.

Zuritz, C.A. \& Sastry, S.K. (1987). Convective heat transfer coefficients for non-Newtonian flow past food-shaped particulates. ASAE Paper No. 87-6538.

Zuritz, C. A., McCoy, S. C. \& Sastry, S. K. (1990). Convective heat transfer coefficients for irregular particles immersed in non-Newtonian fluid during tube flow. J. Food Engng., 11, $159-174$. 